\title{
Preparing Engineers for a Global Future through Guided Opportunities to Innovate for Underserved Communities
}

\author{
M. Bernardine Dias ${ }^{1}$, Ermine A. Teves ${ }^{2}$, and M. Beatrice Dias ${ }^{3}$ \\ ${ }^{1,2,3}$ Carnegie Mellon University \\ 5000 Forbes Avenue, Pittsburgh, Pennsylvania, USA \\ beadias@cmu.edu, ${ }^{2}$ eteves@cs.cmu.edu, 33 mbdias@ri.cmu.edu,
}

\begin{abstract}
The necessary transformation of engineering education is currently the focus of many debates, primarily focused on how best to prepare engineering students to innovate effectively in a future that is increasingly global. A global future means engineers will not be able to solely depend on their personal and local experiences when designing solutions. This article presents our approach to training future engineers to succeed in this complex global future through opportunities to innovate for underserved communities.
\end{abstract}

Appropriately designed technology solutions can truly transform the lives of people in many situations; especially in underserved communities such as communities in the developing world and people with disabilities.

\section{Bernardine Dias}

Carnegie Mellon University

5000 Forbes Avenue, Pittsburgh, Pennsylvania, USA

mbdias@ri.cmu.edu
Yet, designing engineering solutions that are both relevant and accessible to underserved communities is often non-trivial because the innovation team does not share much common ground with the target community.

This leads to bad assumptions and other barriers clouding the innovation process, and ultimately resulting in poor solutions that may even exacerbate issues rather than solving them. Over the past decade, we have explored best practices in innovating for underserved communities, and educating students to follow these best practices. The stages of our innovation process include establishing strong partnerships, assessing needs, recruiting and training innovation teams, participatory iterative innovation, dissemination, and deployment. This article introduces our approach to engineering education, describes our innovation process, details the student experience, illustrates our innovation process through two specific projects, surveys the related work, and concludes with lessons learned and a brief summary of future work.

Keywords - engineering education; student experience; assistive technology; underserved communities; field research; developing world

\section{Introduction}

Many thought leaders today are debating the process by which engineering education must be transformed to prepare engineering students to innovate effectively in a future that is increasingly 
global. Critical skills for future engineers will be their ability to transcend many traditional boundaries, to think outside the box while balancing a variety of tradeoffs, and to design solutions that take into consideration aspects such as community buy-in and sustainability in an increasingly complex world. This article presents an approach to training future engineers to succeed in this complex global future, while simultaneously doing social good, through opportunities to innovate for underserved communities.

While well-designed technology solutions can transform the lives of people in underserved communities, the challenge of successfully designing these solutions to be both relevant and accessible to these communities is often non-trivial. This is primarily because the innovation team involved in the solution design process does not share much common ground with the underserved community in need of the solution. This lack of common ground can lead to bad assumptions and other barriers clouding the innovation process, and ultimately results in a poor solution that sometimes exacerbates the problem rather than solving it.

Through our research group, TechBridgeWorld, at Carnegie Mellon University's Robotics Institute, we have developed and tested aninnovation process thataddresses the needs of both student innovators and partner organizations from underserved communities. Our research endeavors and innovation process therefore empower the partnering underserved community while imparting valuable knowledge to engineering students. Over the past decade, we have explored best practices in innovating for underserved communities, and in educating students to follow these best practices. The stages of our innovation process include establishing strong partnerships, assessing needs, recruiting and training innovation teams, participatory iterative innovation, dissemination, and deployment.

The following sections in this article detail our innovation process, describe student opportunities we provide and their experience when participating in this process, and illustrate this process through two specific projects. The two projects described for illustrative purposes are a Braille Tutor project that aims to increase braille literacy among blind learners, and a Literacy Tools project that aims to enhance functional English literacy among low-literacy learners. The innovation process for each of these projects has spanned multiple years, involved partner communities in a variety of geographical locations, and included innovation teams consisting of students, staff, and faculty from various disciplines. The following section in this article surveysrelated work in the literature, and the article concludes with a summary of lessons learned and a brief description of necessary future work.

\section{Innovation For Underserved Communities}

Motivated to explore the role of technology in serving disadvantaged people in culturally appropriate ways, we established the Tech Bridge world research group at Carnegie Mellon University's Robotics Institute in 2004. Our work is guided by the belief that technology, when engineered in respectful partnership with users, can have the trans formative power of affecting positive change. We work primarily with undeserved communities, which typically include people with disabilities, and economically disadvantaged people, especially in the developing world. When working with communities whose experiences are very different from our own, we have found the need for a specific innovation approach to ensure the success and sustain ability of these research projects. Through this process, we have built partnerships with various underserved communities across the world, by first establishing mutual respect and trust. A considerable amount of time and effort is spent on understanding a community's needs and forging working relationships with individuals within these communities. We then work closely with local partners towardrealizing each community's vision of development by inventing and customizing relevant and accessible technology solutions.

Our innovation process (Dias et al., 2015), illustrated in Figure 1,requires engagement in crosscultural, non-traditional interactions to develop technology solutions that address specific needs identified by each community. In this process, we communicate with users very early in the research process and frequently throughout the course of a project, compared to more traditional engineering endeavors. Our approach also involves inspiring and training future leaders in technology innovation to ensure their skills and contributions also benefit undeserved communities. Key elements of our approach are summarized in the following sections. 


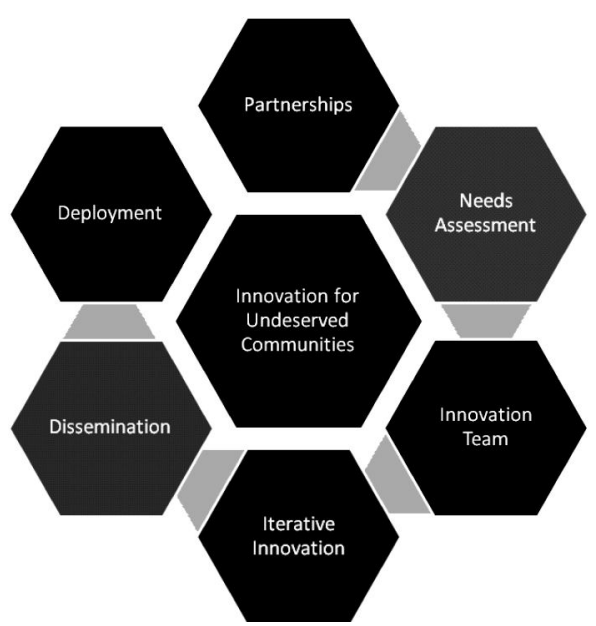

Figure 1. Tech Bridge World's innovation process for working with under served communities

\subsection{Establishing Partnerships and Building Trust}

Vital to the success and sustainability of our projects with underserved communities is a strong partnership with one or more community partners. Partners must have a good understanding of local needs, recognizedleadership in the community, and the capacityto sustain projects locally. Furthermore, partners are instrumental in coordinating key logistics, such as assisting with travel visas and research permits, providing housing and support for team members who travel to project locations, and liaising with any local officials involved with the projects (Cooper et al., 2011). Moreover, partners contribute significantly to technology solutions developed through our projects.

Respecting the end user and working in partnership with them to ensure they are empowered by and feel invested in the technology development process is crucial to building trust and sustaining projects. Oftentimes, engineering projects with underserved communities require little to no investment on the side of the partner community. In all of our projects, we explore meaningful ways for partners to invest in the work. While their investment may not necessarily be monetary, whatever they invest is a valuable resource necessary for the success of the project, and this investmentgives them a sense of ownership in the endeavor.Innovation for underserved communities often involves overcoming many barriers and challenges in order to earn the community'strust and respect, especially if the innovation team consists of foreigners to that community. Keys to establishing trust are a positive attitude, and a true commitment to understand and appreciate cultures and beliefs that may be very different from one's own. This approach has allowed us to gain a better understanding of each community's struggles and passions. In addition, connectingwith end users in this way enables the innovation team to better appreciate and rely on the community expertise that informs the innovation process and resulting solutions.

\subsection{Needs Assessment}

Needs assessment is an important step in our innovation process. Often overlooked, rushed, and underappreciated by engineers, needs assessment is a key component in the process of designing useful and sustainable technology solutions that address the needs of the user community. Through needs assessment, researchers first learn about the needs and challenges identified by community partners. This process often involves individual as well as group interviews and conversations, and can be done iteratively over a period of time. Depending on the location of participants, needs assessment can be done remotely or in person. While thisassessment can be done remotely, on-the-ground data collection is an important factor for success, as it often reveals issues that failed to manifest in preparatory research or communications prior to arrival on-site (Cooper et al., 2011). Needs assessment also provides researchers with experience in learning valuable soft skills such as initiating, fostering and maintaining a direct line of communication with the various communities based on honesty, mutual respect, and trust. We often need to emphasize the value of this step in our innovation process to engineering students and demonstrate to them the value of including an engineering perspective in the needs assessment process.

\subsection{Recruiting and Training EffectiveInnovation} Teams

An important aspect of ourinnovation process is recruiting and training an innovation team with the requisite skills for each project. We also use this step in our innovation process to engageand train the next generation of innovators. In a university setting, this is typically accomplished through student involvement in projects. A key aspect of a successful innovation team for our projects is diversity of skills. Therefore we often recruit and train multidisciplinary teams to carry out our projects. While students in some disciplines have flexibility in their course requirements and schedules, engineering students often face restrictions in their ability to travel overseas 
for projects due to their course requirements and funding restrictions. Thus, we provide opportunities for student involvementthrough alternate avenues such as courses, independent studies, internships, oncampus research projects, etc. By involving students in our innovation process, a new generation of engineers is inspired to take on the challenge of finding solutions to real-world problems that disproportionately affect people in underserved communities. This also provides students with avenues for creating positive impact in underserved communities using their engineering skills; a prospect most engineering students have not considered prior to working with us. Finally, students are encouraged and prepared to become effective ambassadors of this innovationprocess through presentations to peers and other audiences.

\subsection{Iterative Innovation through Participatory Design and Frequent User Testing}

Participatory design is an essential step needed inensuring that the developed technology truly serves the needs of the user community. Technology solutions should not be in their final form before they are brought to the community partner for feedback. Similar to needs assessment, user testing involves interviews and conversations with users to learn about their experience interacting with the technology prototypes and their feedback for improving the solutions to further meet their needs. Through iterative participatory design, the community can directly influence the solutions developed, which further strengthens trust and sustains impact of the project.It is often the case that project scope and direction can change as a result of needs assessment, participatory design and user testing. For example, the needs of the partner may evolve or be clarified, or technological advances may affect the landscape of what is feasible. Such changes ought not to be resisted, but rather embraced because they enable the partnership to grow and sustain by adapting to real conditions on the ground.

\subsection{Dissemination}

Another important, yet often overlooked aspect of our innovation processis dissemination. There are many avenues available fordissemination, including academic venues (e.g. journals, conferences, university classrooms, etc.), traditional media (e.g. television, newspaper, etc.) or social media (e.g. Facebook, Twitter, YouTube, etc.). Regardless of the type of publication, project experiences and outcomes should be shared to contribute to the general body ofknowledge, raise awareness of important issues, and highlight lessons learned. Effective dissemination can also lead to funding and generate the critical mass needed to sustain adoption and future work. This dissemination process should always be respectful of the partner communities, and include their voices in meaningful ways.

\subsection{Deployment}

When versions of a technology solution are sufficiently stable, the innovation team must design and orchestrate a deployment process. Where appropriate, the team should also consider releasing technology solutions under appropriate open source licenses so that these solutions can be customized and enhanced by potential developers and users from around the world, to benefit various other communities. Where possible, the team should also determine what needs to be done for mass production (e.g. designing optimal casing, meeting industry standards, finalizing production location, etc.). Another important consideration for the innovation team is the tradeoff between capabilities and cost so that the final product is affordable to partner communities. Furthermore, the team must also consider working with a variety of partners to determine the best way to sustainably deploy their innovation to potential users. One avenue is to partner with one or more companies or foundations for mass production and distribution.

\section{Student Experience}

We offer several opportunities for students to learn about and practice our innovation process. In terms of courses, we offer two seven-week elective coursesthat are open to undergraduate and graduate students from any discipline. As the name suggests, the "Innovating for Underserved Communities: Field Research Basics" course teaches students the practical skills necessary to conduct effective field research in partnership with underserved communities.

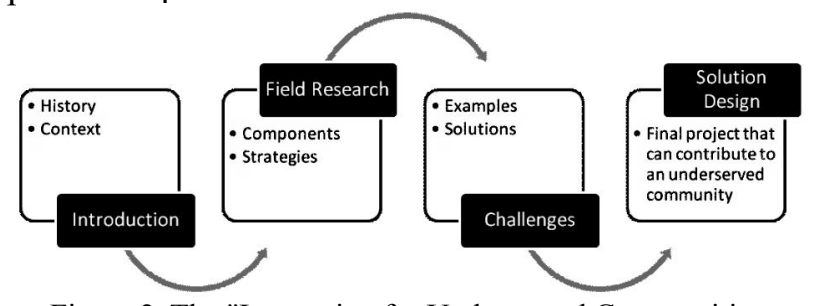

Figure 2. The "Innovating for Underserved Communities: Field Research Basics" course process 
As illustrated in Figure 2, this course begins with an introduction to how computing technology can have a positive impact on the lives of people in developing communities and people with disabilities. Next, students learn about the components of field research including needs assessment, literature review, iterative solution development, evaluation, and dissemination. Students then explore the challenges of field research in this area and learn effective strategies for overcoming these challenges. Overall, students engage in assignments and in-class exercises that help them prepare for future field research endeavors. As a final assignment, students are provided a guided opportunity to design a solution to a specific challenge faced by one of our community partners. Each year the course focuses on a different partner and promising course outcomes may be further developed and tested in the field by our team.

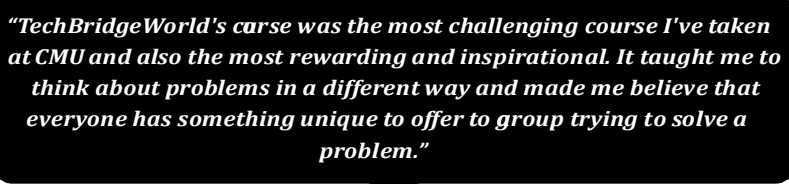

Figure 1. Testimonial from an undergraduate student who took the

"Innovating for Underserved Communities: Field Research Basics" course

The goal of our secondelective course, "Seminar on Innovating for Underserved Communities," is to familiarize students with the literature and ongoing work in this field. The seminar course reviews and critiques several key publications and presentations on this topic and teaches students the necessary skills to analyze and critique this work in useful ways. Class sessions are dedicated to discussing a variety of relevant publications/videos, and assignments involve researching and critiquing projects in this area of study. Throughout this course, students present their findings in a combination of written and oral formats.

Another example of a non-traditional class offering is "Software Development for Social Good" which wasco-taught by a faculty member from the Computer Science Department. In this semester-long course, student teams worked closely with faculty and staff to learn about our various partners in underserved communities, and produce free and open-source software of real and immediate value. Many students even receivedthe opportunity test their work in the field with our local community partners.

These course offerings typically attract students who have a strong desire to use their skills to achieve positive impact in real-world settings. But they also appeal to students who simply wish to fulfill their curriculum requirements. For many of these students in the latter category, their view on technology for underserved communities matures and they achieve a greater understanding of our innovation process.

Apart from course offerings, we also offer a paid internship program called iSTEP (innovative Student Technology ExPerience), which provides students with the opportunity to conduct technology research projects in developing communities (Cooper et al., 2011). Through iSTEP, students gain real-world experience in applying their knowledge and skills for creative problem-solving in unfamiliar settings. We carefully select multidisciplinary teams of students. Teams are typically comprised of a mix of undergraduate and graduate students and recent alumni from various departments. They are set up to work in a globally-distributed team over the summer with team members living and working at the overseas partner location andfaculty and staff working from the Pittsburgh, U.S. campus.Figure 4depicts examples of student experiences in the field through our iSTEP internship program, over several years.

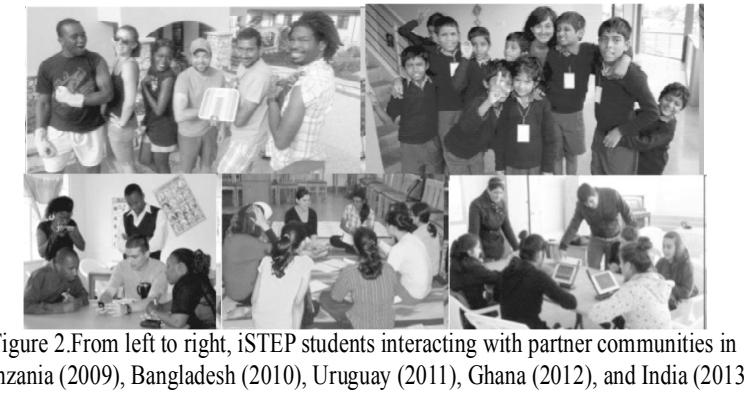

Technology field work in developing communities can be challenging and also rewarding. As a result, we designed the internship such that our team, comprised of faculty and staff who have many years of experience working in this area, supervise and guide iSTEP interns throughout their experience. Interns selected to participate in iSTEP are trained in our innovation process through courses or a one-week orientation and training session. Once training is complete, the field work begins and the iSTEP interns, along with our team, carry out the stages of our innovation process in collaboration with partner communities. Together, the TechBridgeWorld and iSTEP teams contribute technical expertise by inventing new tools and customizing existing technology.

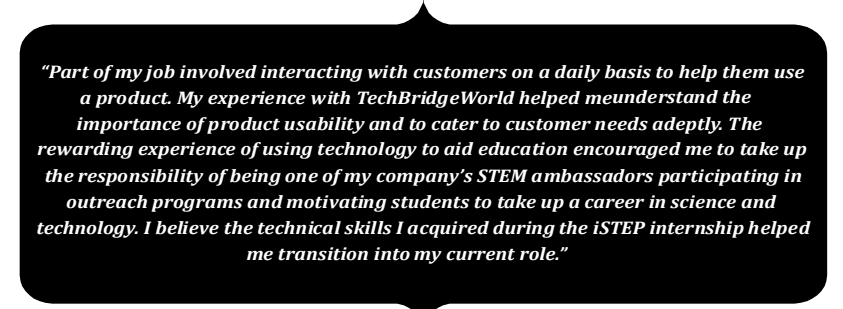

Figure 3. Testimonial from an iSTEP alum about how her experience during the internship has influenced her career 
Two specific case studies that further illustrate our innovation processare presented in the following sections.

\section{Enhancing Braille Literacy In The Developing World}

Our Braille Tutor (BT) project strives to enhance the process of learning the necessary skill of writing braille using the slate and stylus through guided practice. Our longest running project to date, ittackles literacy challenges for children in the developing world who are burdened by both poverty and blindness. The BT project developed two types of devices, described next. Figure 6 shows both devices in the field with different community partners.

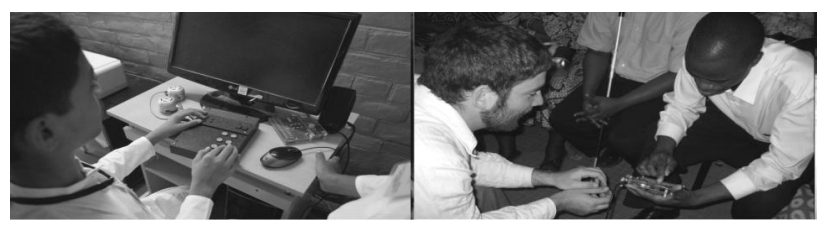

Figure 4. Left: A blind student uses the Stand-Alone

Braille Writing Tutor in India. Right: A student engineersolicits feedback from the community partner on the Braille Writing Tutor in Tanzania.

The Braille Writing Tutor (BWT) is an intelligent tutoring device, which is connected to a computer and audio speakers. The BWT helps users learn and practice writing braille through immediate audio feedback. As the user writes on the electronic slate with the stylus, the BWT speaks out the written letters, numbers or words. The tutor also guides writing and corrects mistakes. The immediate audio feedback also serves as a diagnostic tool for instructors, giving them a real-time understanding of what concepts the user did and did not grasp.

The Stand-Alone Braille Writing Tutor (SABT) is an essential upgrade to the BWT. The SABT preservesall BWT features but is battery-powered and has onboard computing. Users can plug in headphones or speakers to access audio output from the device. The SABT also addresses the challenges of frequent power failures and lack of access to stable computers in many developing communities.

Before the BT project began, a partnership was established with the Mathru School for the Blind in Bangalore, India. This collaboration with the Mathru School has been going strong since 2006. We also formed partnerships with several organizations from around the world who were interested in collaborating with us. Other partners included a social development organization in Bangladesh, a rehabilitation services organization in the U.S., as well as schools for the blind in Bangladesh, China, Qatar, Tanzania, the U.S., and Zambia.

Initial needs assessment was conducted remotely with the Mathru School based in India. Video footage of educational activities was captured by a personal contact of our team who livedin Bangalore.Needs were clarified through a series of phone calls and email exchanges between our team and the Mathru School. Ultimately, it was determined that the school's greatest need, which we had the expertise and the ability to address, was to teach the skill of writing braille using the slate and stylus through guided practice. On-the-ground needs assessment conducted by our team of researchers also took place with the Mathru School. Through these visits, researchers were able to gain a better understanding ofthe school'sneeds in order to develop practical, sustainable, and relevant solutions to address those challenges.

User testing of the BT technologies with Mathru teachers and students took place during several visits to the school. We obtained valuable feedback confirming the relevance of the BT technologies and its potential, as well as critical design changes. During one testing, researchers learned that the design of the BWT's wired stylus needed to be altered because children at the school were taught that wires are dangerous and were therefore concerned about using the device. Furthermore, researchers learned that the serial cables used to connect the original version of the BWT to the computer were difficult for the teachers to align correctly when setting up the device. The teachers also requested a method to familiarize younger learners (who were still developing dexterity) with the concept of a braille cell and dots. To address these findings, the second version of the BWT underwent a major design change in which any regular metal stylus could be used for input, the device connected to a computer through a USB cable, and six buttons representing a large braille cell were added as an alternate input area.

Researchers later returned to test the second version of the BWT which confirmed that the design changes incorporated were effective. Needs assessment conducted during the visit indicated the need for educational games, which were consequently developed and added to the BWT's software. In later 
years, researchers also learned about the school's need for a device that did not need to be connected to a computer and worked despite power failures. This information led to the design of the SABT. Researchers returned to the Mathru School to test the SABT beginner interface. User testing confirmed the relevance of the SABT and several modes were enhanced and new modes developed to meet the curriculum needs of the school.

Although our research group is based at CMU, our engineering process is sustained through student involvement. Demand from students interested in conducting projects with our team is very high. As a result, our approach to field research and components of the BT project were integrated in several courses, independent studies, honors theses, and research projects. In all cases, students are mentored and led by faculty and staff on our team. Students' activities are designed with educational objectives in mind, but also help meet project objectives. Over the years, we have involved over $40 \mathrm{CMU}$ students and alumni in the BT project through courses, independent studies, honors theses, and through the iSTEP internship program. Participants ranged from undergraduate freshmen to $\mathrm{Ph} . \mathrm{D}$. students and came from backgrounds including computer science, public policy, the humanities, business, electrical engineering, art, and design. Notably, four of the six iSTEP internships involved working on the BT project in India, Bangladesh and Tanzania, over an intensive 10-week period.

We have published several papers about the BT project in conferences, including the International Joint Conference on Artificial Intelligence, International Conference on Information and Communication Technologies and Development, Grace Hopper Celebration of Women in Computing Conference, and International Conference on Intelligent Robots and Systems. Our work was also published in the Information Systems Frontier Journal. Furthermore, these publications are being cited by researchers from several universities in the U.S. and around the world. In 2014, the BT received national recognition by winning the Touch of Genius Prize for Innovation. Organized by the National Braille Press in the U.S., the Touch of Genius Prize recognizes innovations in the field of tactile literacy for the blind.

Over the years, we have received much media attention for this project and for the communities we are serving, which have helped to raise greater awareness about the needs of blind people, particularly in terms of literacy, and especially in the developing world. This work has also encouraged others to interact with and support blind children with compassion, and improve conditions in schools for the blind by investing their time and resources. Perhaps most notably, this work has served as an inspiration for many engineers and technologists.

We have received many inquiries from parents, mentors, teachers, etc. from around the world about the BT project. They acknowledge the project's potential and often want to buy or loan the BWT and SABT devices for their child or student. We have released an early version of the BWT software and hardware under open source licenses and will continue to release further versions as they are stabilized. To engage the open source community, we also developed an initial BWT simulator so that a physical device is not needed for developers to improve the software. Furthermore, several organizations have reached out to us to commercialize the BWT and SABT, but we have not accepted any offers thus far since it was unclear that they would ensure that the products will be affordable to our partner organizations (such as the Mathru School) who have limited purchasing power.

\section{Enhancing English Literacy In Low-literacy Communities}

The previously described BT project is our longest running project. As our second example we chose our most popular project; our Literacy Tools (LT) project, whichharnesses the power of motivational games for education in a scalable manner. This project provides educators and learners with simplemotivational games that can easily embed customized educational content. The project involves three components that engage the three different stakeholders involved.

First, the Teacher Portal allows teachers to upload educational content used in their classrooms in a variety of common formats (e.g. multiple choice, fill in the blank, select all that apply, etc.). The Teacher Portal also allows instructors to monitor studentprogress and can be used to assign exercises to the class. Second, the Student Portal allows learners to complete assigned exercises through a variety of games accessible ondifferent platforms (e.g. desktops, laptops, tablets, and smartphones). The games, designed to be entertaining, embed the educational content separately from gameplay, and 
requires learners to complete educational exercises to advance in the game of their choice. One example is a racecar game theme that is designed to be an entertaining racing game. However, students have to answer educational questions, provided by their teacher, in order to earn enough gas to continue driving the car. The game pauses as students answer a question and then continues afterwards. Students have the choice to play their assignments through any game theme of their choice, or to complete the assignment as an online exercise without the game aspect.Lastly, the Developer Portal is a platform for developers to create entertaining games for this project. Through this model, developers do not have to take into account educational content or pedagogy; they can simply focus on making the game fun to play.Figure 7 shows games developed for different community partners being tested in the field.

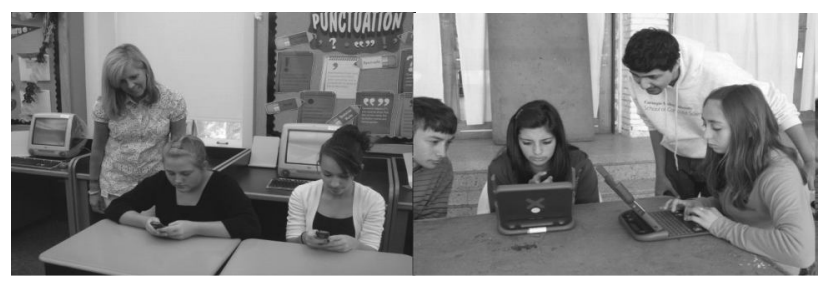

Figure 7. Left: A teacher looks on as her students play a game developed for a school in the U.S. Right:

A student technologist observes students playing a game developed for a school in Uruguay.

For this project, we established partnerships with several organizationsfrom around the world who invited us to collaborate with them. Partners included a women's university in Chittagong, Bangladesh, a primary school in Dar es Salaam, Tanzania, and a governmental organization in Montevideo, Uruguay. In Doha, Qatar, we established partnerships withseveral organizations who worked with adult migrant workers, high school graduates, as well as elementary and middle school students with learning disabilities, respectively. In the U.S., we established partnerships with a school for the deaf and an agency that educates refugees living in the greater Pittsburgh area.Given the unique and diversepopulations we worked with, establishing partnership and trust was vital to ensure thatthe LT project was successful in meeting partner community needs.

To ensure those needs were met, needs assessment was conducted with all partners. Since our team is based in the U.S., we coordinated with team members who were temporarily located in the partner location in Tanzania in 2009, Bangladesh in 2010, and
Uruguay in 2011. For partners in Qatar, we coordinated with team members who were permanently based at CMU's campus in Qatar since 2012. And in the U.S., wewere able to conduct on-site needs assessment with partners since 2009.For all partners, many of our team members facilitated interviews, observations, focus groups, and surveys to assess needs. Consistent among all partners was the need for customizability given teachers' various constraints and the need for a variety of entertaining game options to meet students' different preferences.

Soon after technology prototypes were developed based on needs assessment, user testing was conducted with partners to evaluate effectiveness.During the 2009 project iteration in Tanzania the team developedthe first version of the Teacher Portal, as well as the first game (a soccerthemed game). In the 2010 project iteration in Bangladesh, the Teacher Portal was enhanced based on feedback received from partners, the first version of the Student Portal was developed, and a simple computer exercise tool was createdfor students who wished to practice their teacher's content in a nongame format. For the 2011 project iteration in Uruguay, the Student Portal was enhanced so that students could access teacher content on the One Laptop Per Child XO laptops, which were being utilized in the schools. Similarly, the Teacher Portal was enhanced so that teachers could customize content on the XO laptops as well. Facebook games were also considered as a way to further engage students to interact with their teacher's content and introduce competition through the social platform.

In the U.S. and Qatar,technology innovation took on a more iterative process since work with partners continually took place since 2009 and 2012, respectively. Enhancements were made to the Teacher Portal and Student Portal based on feedback from partners, several entertaining games were developed based on partner preferences and enhanced based on feedback, and the Developer Portal was created to allow developers to submit games.

Like the BT project, we integrated many components of the LT project in several courses, independent studies, honors theses, and research projects.Through iSTEP, three of the six iSTEP internships involved working on the LT project in Bangladesh, Tanzania, and Uruguay.Over the years, our team has involved over $60 \mathrm{CMU}$ students and alumni from multi-disciplinary backgrounds, ranging 
from undergraduate freshmen to graduate students. These students were involved with all aspects of enhanced engineering in the LT project from partnership building to needs assessment to prototype development and user testing.

LT project outcomes have been presented in conferences such as ACM DEV, Qatar Foundation Annual Research Conference, TESOL International Convention \& English Language Expo, and theInternational Conference on Computer Supported Education. Through iSTEP, CMU students and alumni assisted us in disseminating project outcomes and experiences through traditional and social media, which received further attention from the press in the U.S., Qatar, and countries of the communities we partnered with.

Consistent with our innovation model, we have released early versions of the Teacher Portal and Student Portal software under open source licenses. Several games developed for the LT framework have also been released under open source licenses. We will continue to release further versions of the portals and games as they are stabilized.

\section{Related Work}

In today's increasingly global society, academic institutions are recognizing the necessity to shift from "chalk and talk" environments focused on the transfer of knowledge to student-centric ones that promote understanding (Padmaja et al., 2015; Karmokar et al., 2015). Not only must the next generation of engineers have technical skills, they must also have more exposure to real-world thinking, opportunities to practice problem-solving skills in multi-disciplinary settings, training on oral and written communication, and mindfulness of ethical, environmental, and social issues (Farrell et al., 2015; Bidanda, 2015). Furthermore, engineers should be challenged to solve problems creatively through inquiry based learning (Karmokar et al., 2015).

When working with underserved communities around the world, the need for mindful engineers is especially critical. Information and Communication Technologies for Development (ICTD) is a growing field dedicated to bridging the divide between developed and developing communities through appropriately applied technology (Dias and Brewer, 2009). Resulting projects span many areas ranging from telemedicine (Surana et al., 2008), to assistive technology (Pal et al., 2011), to microfinance (Ratan et al., 2010), to education (Kam et al., 2009). Engineers are often part of the multi-disciplinary research teams involved in ICTD. A major critique of the ICTD field is project sustainability with partner communities after the researchers leave (Dias and Brewer, 2009).

Today, engineering students have access to several opportunities that challenge them to apply skills learnedin the classroom in a real-world context. Service learning (SL) provides students with structured educational opportunities to address societal needs (Liu, 2005). SL offerings aim to promote student learning and development while benefitting the community at the same time. Project partners for such opportunities range from NGOs in a local community to international organizations(Mehta and Sukumaran, 2007; Coyle et al., 2005). However, some offerings place greater emphasis on the quality of the student experience, at the expense of benefit to the community partner (Liu, 2005; Purewal et al., 2007). This can lead to a dual concern where community partners feel that they have wasted precious resources, and students learning that their experience is more important than the benefit to the partner. Our approach prioritizes both the experience of our students, and the experience of our community partners.

In universities, SL typically manifests as courses with a community project component (Liu, 2005; Purewal et al., 2007; Karmokar et al., 2015), service projects (Coyle et al., 2005; Karmokar et al., 2015), and engineering clinics (Mehta and Sukumaran, 2007). Examples of each offering are detailed below.

Auckland University of Technology integrates Engineers Without Borders (EWB) in the engineering core course 'Introduction to Design', which aims to develop effective communication skills and an "understanding of the role and responsibilities of an engineering in society" (Karmokar et al., 2015). Since the course is designed for first year engineering students, the community project component of the course was a real-world case study in an underserved community. EWB personnel gave a presentation on the community and challenges and provided students with a resource pack on the community. The students did not have direct communication with the partner.

Engineering Projects in Community Service (EPICS), which originated in Purdue University, 
allows undergraduate students to earn "academic credit for their contributions to long-term, team-based design projects that deliver innovate, technologybased solutions to problems identified by not-forprofit organizations in the community" (Coyle et al., 2005). Multidisciplinary student teams ranging from freshmen to seniors are matched with local community partners on projects that undergo a "startto-finish" design experience involving needs assessment, design, development, testing and deployment (with the project partner). EPICS has been able to replicate its model and is now adopted by several universities in the U.S.

Rowan University's Engineering Clinic"emphasizes engineering practice and professionalism in a multidisciplinary setting" through a sequence of courses that engineering students take every semester of their undergraduate studies (Mehta and Sukumaran, 2007). Upperclassmen are able to participate in SL projects that have regional, national or international impact, often participating in endeavors throughEWB-USA. Through EWB-USA, students at Rowan gain experience in utilizing their engineering skills to adapt technology to meet the needs and resources of the host community (Mehta and Sukumaran, 2007). EWBUSA-approved projects originate from a host community and are assigned to an EWB student chapter. These projects are longer-term with more direct and sustained communication between engineering students and partner communities, often including trips to partner sites. For students who do not travel, communication is maintained via phone and e-mail (Mehta and Sukumaran, 2007).

In the Auckland University of Technology course, student training involved weekly lectures and completing tutorial problems individually or in groups (Karmokar et al., 2015). The course provided a facilitator to advise students on any project-related issues. In the EPICS model, students attend weekly one-hour lectures that cover topics related to engineering design, communication, and community service (Coyle et al., 2005). In Rowan University, their engineering clinic spans eight semesters and is required for all engineers. Each semester focuses on a different theme, ranging from engineering measurements, to reverse engineering a commercial product or process, to carrying out capstone projects (Mehta and Sukumaran, 2007). Our approach provides engineering students, as well as students of other disciplines, training and practical experience in innovating for underserved communities in a variety of ways that meet their schedules and constraints.

\section{Conclusions and Future Work}

In this article we have described ourinnovation process for projects that focus on underserved communities. Since the TechBridgeWorld research groupwas founded over a decade ago, close to 100 students have experienced our innovation process through our academic offerings, in which they contributed their knowledge and expertise to research projects that serve the needs of partner communities. In turn, the outcomes of these projects have touched the lives of many people in underserved communities around the world. Many of these students have graduated and gone on to work in industry, academia, and the non-profit sector. Moreover, our partners' perspective of technology has changed. For example, students and teachers at the Mathru School want to explore how robots can assist them in their everyday activities, and refugees learning English are finding that they are able to learn while at the same time familiarizing themselves with computing technology.

Through this work over the last decade, we have learned several important lessons about engaging and training the next generation of technologists to successfully engineer solutions for underserved communities. Based on these lessons learned, we make the following recommendations for others who endeavor to do the same:

( Build strong partnerships to ensure the success of a project. Involve students in the partnership building process so that they can also gain a better understanding of the partner's struggles and passions. This enables innovation teams to create more effective and sustainable solutions.

Q Avoid overlooking and rushing needs assessment. Students may initially view this process as timeconsuming, however it is important to emphasize that accomplishing needs assessment properly can save effort and resources for everyone involved, and lead to relevant technology solutions.

( Train students to empower the partner community through participatory design, user testing, and iterative innovation. Explain to students the importance of periodically obtaining feedback from partners to ensure that technology solutions truly meet the community's needs. 
( Emphasize the importance of disseminating outcomes of engineering projects to students. Furthermore, train students to do so in a way that is respectful of partner communities and includes the voices of the partner in meaningful ways.

૫ Lead by example by releasing stable versions of technology solutions under appropriate open source licenses. Explain to students that doing so allows potential developers and end users to have access to these solutions and further customize and enhance them. Also remind students that when commercializing a technology solution, to ensure that the products will be affordable to partners and those with limited purchasing power.

While our endeavors over the past decade have yielded many successes and important lessons learned, there is still much that can be done to enhance engineering education such that innovators can work more effectively across traditional boundaries; including creating solutions for underserved communities. First and foremost, more sponsored research opportunities need to be made available for addressing the needs of disadvantaged communities via engineering solutions. While a few such opportunities have started to emerge, much more progress is needed in this area. Another important aspect is enhancing the publication opportunities for this area of study by creating awareness among reviewers and recognizing the value and challenges of this work via relevant conferences, workshops, journals, etc. Several conference and journals are now starting to recognize this work. Examples include the Developing Countries Forum at the 2015 International Conference on Robotics and Automation, the ICTD conferences, the Information Technologies and International Development (ITID) journal, and the ACM DEV conferences . Relevant competitions, internships, and career paths are also needed to encourage and sustain the efforts of budding engineers in this area. It is encouraging to see progress in this area as well through efforts from multinational corporations and local start-ups alike.

Effective partnerships between academia, industry, governments, non-profits, and various community groups will become increasingly necessary for sustainable and effective engineering solutions in the future. Providing opportunities for engineering students and other innovators to effectively work on projects that address the needs of underserved communities is a great means for challenging them to work across a variety of traditional boundaries, think outside the box, balance a variety of tradeoffs, get real-world experience, prepare for a global future, and do social good; all in one experience.

\section{Acknowledgments}

We thank the many inventors and collaborators who have been involved with the Braille Tutor project since it began in 2006 and the Literacy Tools project in 2009. We also thank our project partners and the many teachers and students who were involved in our research.

This research was supported in part by the Qatar National Research Fund's National Priorities Research Program (NPRP) through grants \#30-6-7-91 and \#04-439-1-071, the Qatar National Research Fund's Undergraduate Research Experience Program (UREP) through grant \#4-15-6, the Qatar Foundation for Education, Science, and Community Development, the Fetzer Institute, and discretionary gifts to the TechBridgeWorld research group at Carnegie Mellon University. The opinions expressed in this paper are those of the authors and do not necessarily represent the views of the sponsors.

\section{References}

B. Bidanda, "Engineers Without Borders," in Proceedings of the International Conference on Transformations in Engineering Education, R. Natarajan, Ed. New Delhi: Springer India, 2015, pp. $\begin{array}{llllll}5 & 7 & - & 5 & 9\end{array}$ http://link.springer.com/chapter/10.1007\%2F97881-322-1931-6_8

Y. Cooper, M. B. Dias, E. A. Teves, S. Belousov, and M. F. Dias, "Enhancing Participation and Education in CS Through Guided Research Projects in Underserved Communities," in Proceedings of the $42 \mathrm{Nd}$ ACM Technical Symposium on Computer Science Education, New York, NY, USA, 2011, pp. 577-582. doi: 10.1145/1953163.1953324

E. J. Coyle, L. H. Jamieson, and W.C. Oakes, "EPICS: Engineering Projects in Community Service," in Int. J. Engng. Ed. vol. 21, no. 1, 2005.

M. B. Dias and E. Brewer, "How Computer Science Serves the Developing World," Commun. ACM, vol. 52, no.6, pp.74-80, Jun.2009.doi : $10.1145 / 1516046.1516064$

M.Dias, E. Teves and M. Dias, "Towards Technology 
with a Global Heart through Compassionate Engineering," in Proceedings of the Engineering 4 Society Conference, Leuven, Belgium, 2015.

S.Farre11,H.J.Hoyer, and D.M.Fraser, "Transformations in Engineering Education Globally,"in Proceedings of the International Conference on Transformations in Engineering Education, R. Natarajan, Ed. Springer India, 2015, $\mathrm{p} \quad \mathrm{p} \quad$. $\quad 3 \quad-\quad 7$. http://link.springer.com/chapter/10.1007\%2F97881-322-1931-6_1

M. Kam, A. Kumar, S. Jain, A. Mathur, and J. Canny, "Improving literacy in rural India: cellphone games in an after-school program," in 2009 International Conference on Information and Communication Technologies and Development (ICTD), 2009, pp. 139-149. doi:10.1109/MC.2008.184

S. Karmokar, A. M. Connor, and C. Whittington, "From STEM to STEAM: strategies for enhancing engineering \& technology education," May 2015. http://hdl.handle.net/10292/8744

C. Liu, "Enriching Software Engineering Courses with Service-learning Projects and the Open-source Approach," in Proceedings of the 27th International Conference on Software Engineering, New York, NY, USA,2005,pp.613-614.d: 10.1145/1062455.1062566

Y. Mehta and B. Sukumaran, "Integrating Service Learning in Engineering Clinics," IJSLE, vol. 2, no. 1, Apr. 2007.

J. Pal, M. Pradhan, M. Shah, and R. Babu, "Assistive Technology for Vision-impairments: Anagenda for the ICTD Community," in Proceedings of the 20th
International Conference Companion on World Wide Web, New York, NY, USA, 2011, pp. 513-522. doi:10.1145/1963192.1963365

A. Padmaja, V. S. V. L. Ramana, and P. R. Reddy, "Importance of Research at Undergraduate Level," in Proceedings of the International Conference on Transformations in Engineering Education, R. Natarajan, Ed. Springer India, 2015, pp. 631-632. http://link.springer.com/chapter/10.1007\%2F97881-322-1931-6_101

T. S. Purewal Jr., C. Bennett, and F. Maier, "Embracing the Social Relevance: Computing, Ethics and the Community," in Proceedings of the 38th SIGCSE Technical Symposium on Computer Science Education, New York, NY, USA, 2007, pp. 556-560. doi: 10.1145/1227504.1227496

A. L. Ratan, K. Toyama, S. Chakraborty, K. S. Ooi, M. Koenig, P. V. Chitnis, and M. Phiong, "Managing Microfinance with Paper, Pen and Digital Slate," in Proceedings of the 4th ACM/IEEE International Conference on Information and Communication Technologies and Development,New York, NY, USA, 2010,pp. 37:1-37:11.doi:10.1145/2369220.2369255

S. Surana, R. Patra, S. Nedevschi, and E. Brewer, "Deploying a Rural Wireless Telemedicine System: Experiences in Sustainability," Computer, vol. 41, no. $6, \mathrm{p} \mathrm{p} .48-56$, J u n . 20008 . d o i : 10.1109/ICTD.2009.5426712 